\title{
Frédéric Gugelot, La messe est dite. Le prêtre et la littérature d'inspiration catholique en France au $\mathrm{XIX}^{\mathrm{e}}$ siècle
}

Rennes, Presses universitaires de Rennes, coll. «Interférence », 2015, $194 \mathrm{p}$.

\section{Cécile Vanderpelen-Diagre}

\section{(2) OpenEdition} Journals

Édition électronique

URL : http://journals.openedition.org/assr/27374

DOI : $10.4000 /$ assr.27374

ISSN : $1777-5825$

Éditeur

Éditions de l'EHESS

\section{Édition imprimée}

Date de publication : 1 octobre 2015

Pagination : 309

ISBN : 978-2-7132-2515-4

ISSN : 0335-5985

\section{Référence électronique}

Cécile Vanderpelen-Diagre, «Frédéric Gugelot, La messe est dite. Le prêtre et la littérature d'inspiration catholique en France au xix ${ }^{e}$ siècle », Archives de sciences sociales des religions [En ligne], 172 | octobredécembre, mis en ligne le 24 mai 2016, consulté le 24 septembre 2020. URL : http:// journals.openedition.org/assr/27374; DOI : https://doi.org/10.4000/assr.27374

Ce document a été généré automatiquement le 24 septembre 2020

(c) Archives de sciences sociales des religions 


\section{Frédéric Gugelot, La messe est dite. Le prêtre et la littérature d'inspiration catholique en France au XIX ${ }^{\mathrm{e}}$ siècle}

Rennes, Presses universitaires de Rennes, coll. « Interférence », 2015, $194 \mathrm{p}$.

Cécile Vanderpelen-Diagre

\section{RÉFÉRENCE}

Frédéric Gugelot, La messe est dite. Le prêtre et la littérature d'inspiration catholique en France au xIX ${ }^{\mathrm{e}}$ siècle, Rennes, Presses universitaires de Rennes, coll. «Interférence ", 2015, $194 \mathrm{p}$. 
1 En dépit de la sécularisation et de la baisse toujours constante de la pratique religieuse comme des vocations, la figure $\mathrm{du}$ prêtre reste très présente dans l'imaginaire de l'homme et de la femme $\mathrm{du} \mathrm{xx}^{\mathrm{e}}$ siècle. Du torturé abbé Donissan incarné par Gérard Depardieu dans le film Sous le soleil de Satan (Palme d'or du Festival de Cannes de 1987) en passant par le débonnaire Don Camillo joué par Fernandel (d'après le livre de Giovanni Guareschi) et le gourmand Don Patillo des pâtes Panzani, les médias ont entretenu la mémoire de ces hommes. Récemment, la série télévisée française Ainsi soient-ils (David Elkaïm, Bruno Nahon, Vincent Pymiro et Rodolphe Tissot) a réactivé

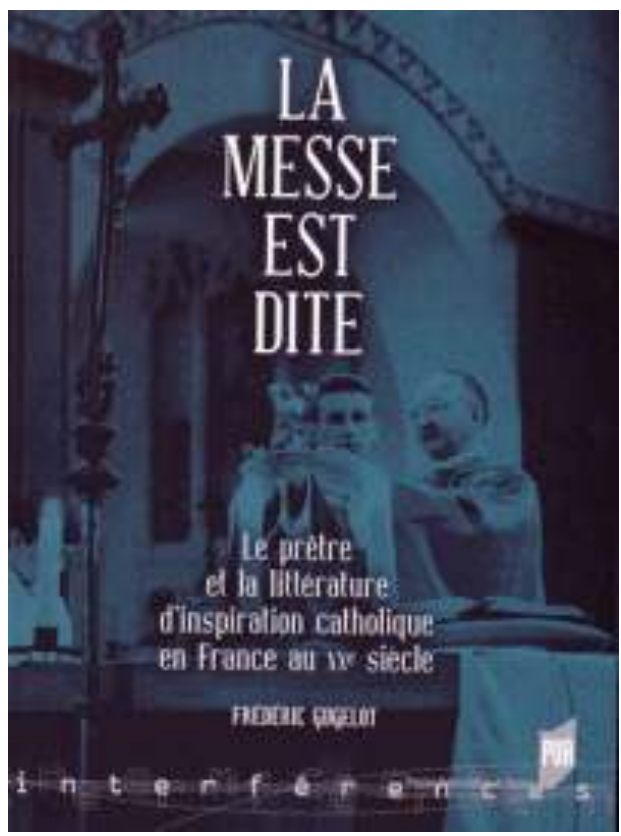
l'intérêt pour le personnage du prêtre, démontrant une fois encore sa richesse romanesque et cinématographique. La manière dont cette richesse est exploitée est évidemment en miroir des questions que pose le catholicisme aujourd'hui. Car, en dépit de la posture intemporelle qu'on lui prête - et qui explique sans doute en partie son succès comme personnage de fiction -, les fonctions et représentations du prêtre sont évidemment profondément déterminées historiquement. Il en est de même de la force d'évocation ou de symbolisation religieuse dont les croyants le revêtent. Frédéric Gugelot s'est attaché à le démontrer dans un ouvrage qui impressionne par la diversité des textes et archives inédites convoqués et l'efficacité d'une grille d'analyse qui met au jour d'une manière très convaincante les enjeux socioreligieux des débats théologiques et littéraires provoqués par les romans analysés.

2 Tout l'intérêt du livre est de ne pas s'être concentré sur une histoire interne des textes et d'avoir cherché leurs résonnances, leurs conditions de production et d'énonciation en l'état des représentations dans l'Église tant enseignée qu'enseignante.

3 À la fin du XIX ${ }^{\mathrm{e}}$ siècle, en pleine crise de Séparation entre l'État et l'Église, Paul Bourget et Henri Bordeaux imposent avec succès des romans qui mettent en scène les vertus de l'ordre et de la morale qui leur sont chères. Nationalistes, conservateurs, voire réactionnaires, attachés à la terre, à la tradition et à la paysannerie, les prêtres sont invoqués pour régénérer une société supposée en pleine déliquescence. L'Église, qui a fait de la presse une arme de reconquête des âmes, accueille ces images avec enthousiasme. Dans le même temps, les écrivains (souvent convertis) de ce qu'on appelle communément "la renaissance catholique " pensent, eux, que la reconquête doit passer par la qualité esthétique, par des œuvres aptes à rivaliser dans le champ littéraire et à convertir des hommes et femmes égarés dans les impasses du rationalisme. Huysmans et Bloy racontent les tourments spirituels de prêtres idéalistes et humains - et donc faillibles - torturés par la tension qu'ils vivent en leur chair entre le péché et la grâce. Leur humanité semble propre à susciter un processus d'identification, mais passe par une remise en question de la nature impeccable du clerc ; une initiative difficilement acceptable pour la hiérarchie. 
4 Le curé bernanosien creuse cette veine. Sa vie et ses déchirements spirituels servent à «déceler l'action de la grâce en ce monde déchiré » (p.46) qu'est la France à jamais perdue pour la chrétienté. Le dévoilement du moi intérieur est chirurgical et se mêle à une véritable réflexion théologique, apanage normalement du seul clergé. Ce qui est mis en lumière, c'est l'acte d'incarnation par le prêtre lui-même, non par son action sur le peuple de Dieu, mais par son sacrifice personnel. Cette démarche qui consiste à atteindre la vérité divine par l'immanence est également poursuivie par le prêtre d' Augustin ou le maître est là de Joseph Malègue. Chez Maxence Van der Meersch, «le prêtre est toujours humble, petit, peu attaché au dogme» (p.54), c'est sa vie de renoncement qui laisse Dieu imprégner jusqu'à son corps qui est exemplaire, pas ses actes. Le corps quant à lui est bien humain : il n'ignore pas les affres de la sexualité ; péché ultime. De telles figures, en raison de leur force romanesque, trouvent une réception favorable dans le champ littéraire. En revanche, la hiérarchie y est en général hostile. Ainsi se dessine le début d'un long mouvement de balancier, allant du divorce au mariage heureux, entre l'Église et « ses » écrivains.

5 Après la Deuxième Guerre mondiale, une nouvelle figure de prêtre émerge avec le prêtre-ouvrier. Celui-ci s'inscrit dans « l'héritage d'une littérature de témoignage qui a désigné la banlieue comme terrain missionnaire» (p.87). Gilbert Cesbron donne ses lettres de noblesse au genre avec Les Saints vont en enfer (1952), vendu à 1648000 exemplaires. Il parvient à créer une sorte de "mythe littéraire» (p. 91) qui combine retour aux origines du christianisme, langage et culte "populaires", proximité avec le monde ouvrier, frictions avec la hiérarchie et emprunt au style du reportage et de l'enquête. L'influence du livre de Henri Godin et Yvan Daniel, La France pays de mission est patente. Chez Cesbron comme chez ses homologues, un élément plus problématique apparaît dans la foulée : la proximité avec l'éthique communiste. La condamnation des prêtres-ouvriers par Pie XII en 1954 provoque une profonde remise en question par l'Église des romans sacerdotaux. Des écrivains tels Queffelec et Bordeaux sont incités à écrire des romans alternatifs; un retour en quelque sorte des œuvres de la veine de l'ordre et de la morale, sur un fond régionaliste assumé. Mais le succès n'est pas au rendez-vous, leur allégeance à une littérature traditionaliste et à une foi très institutionnalisée est peu goûtée tant du grand public que du public spécifiquement chrétien, avide d'autres nourritures spirituelles.

Dans les années 1960, la chute des vocations voisine, sans surprise, avec la remise en question radicale de la fonction de médiation exercée par le prêtre. Le prêtre a-t-il déserté la littérature? Non, il revient dans les romans de Michel de Saint-Pierre, qui tente de lui redonner vie dans ses habits traditionnels, ceux du début du siècle, ceux que Vatican II est en train de jeter aux orties. Un public, certes minoritaire mais présent, suit l'écrivain normand qui parvient à se conférer une légitimité - en fait une étiquette - catholique en explicitant le rôle d'un clerc dans la relecture de ses manuscrits. Ce public est celui des catholiques «d'identité », tels que Philippe Portier qualifie les pèlerins attachés à la certitude de la foi, cherchant la visibilité d'une identité forte, plutôt en réaction face aux changements établis par le Concile Vatican II.

Dans un sens radicalement inverse, dans le même temps, des prêtres prennent la plume pour témoigner de leur foi et travailler à une renaissance spirituelle. Jean Le Marchand, alias Jean Sulivan, l'abbé Fleury, alias Jean Montaurier, l'abbé Louis Fafournoux alias Louis Fafournoux réinterrogent la fonction du prêtre et, que ce soit dans la veine spirituelle pour Sulivan ou dans celle de l'ordre et de la morale pour Montaurier et 
Fafournoux, ils tentent de justifier leur rôle qui, dans la société sécularisée qui est la leur, n'a plus de sens.

8 Le prêtre est-il désormais une figure du passé? La chute des vocations semble le prédire. Pourtant, l'histoire comparée des religions montre qu'il est difficile pour elles de se passer de médiateurs entre les croyants et Dieu, entre le Ciel et la Terre. À lire l'ouvrage de Frédéric Gugelot, on se prend à penser que cette fonction est appelée à survivre, mais sans doute selon des modalités inédites, aptes à permettre de dépasser la seule référence folklorique à laquelle semble renvoyer aujourd'hui cette figure. Mais le très beau parcours auquel nous invite l'historien indique que, par effet de structure, cette figure sera toujours déchirée et déchirante puisque par nature elle personnifie toutes les tensions du christianisme: foi vs dogme, croyance vs appartenance et adhésion institutionnelles, individu vs collectivité. Entre ces pôles, le clerc opère sans cesse un rôle de médiateur et agrège toutes les polémiques. Qu'en est-il des autres religions et des autres pays? Il aurait été possible en conclusion d'esquisser une comparaison internationale ou interreligieuse. La typologie proposée fonctionne-t-elle pour les écrivains catholiques belges, britanniques, italiens, suisses? Existe-t-il une figure de l'écrivain protestant? Sans aucun doute, mais avec enjeux tout différents. La figure littéraire du pasteur ne pourrait donc elle-même avoir les mêmes enjeux pastoraux et théologiques que celle du prêtre. 